\title{
Synaptic dysfunction and septin protein family members in neurodegenerative diseases
}

\author{
Mikael Marttinen ${ }^{1,2,3}$, Kaisa MA Kurkinen ${ }^{1,2,3}$, Hilkka Soininen ${ }^{2,3}$, Annakaisa Haapasalo ${ }^{2,3+}$ and Mikko Hiltunen ${ }^{1,2,3^{*}+}$
}

\begin{abstract}
Cognitive decline and disease progression in different neurodegenerative diseases typically involves synaptic dysfunction preceding the neuronal loss. The synaptic dysfunction is suggested to be caused by imbalanced synaptic plasticity i.e. enhanced induction of long-term depression and concomitantly decreased long-term potentiation accompanied with excess stimulation of extrasynaptic N-Methyl-D-aspartate (NMDA) receptors due to various disturbances in pre- and postsynaptic sites. Recent research has identified neurodegenerative disease-related changes in protein accumulation and aggregation, gene expression, and protein functions, which may contribute to imbalanced synaptic function. Nevertheless, a comprehensive understanding of the mechanisms regulating synaptic plasticity in health and disease is still lacking and therefore characterization of new candidates involved in these mechanisms is needed. Septins, a highly conserved group of guanosine-5'-triphosphate (GTP)-binding proteins, show high neuronal expression and are implicated in the regulation of synaptic vesicle trafficking and neurotransmitter release. In this review, we first summarize the evidence how synaptic dysfunction is related to the pathogenesis of Alzheimer's, Parkinson's and Huntington's disease and frontotemporal lobar degeneration. Then, we discuss different aspects of the potential involvement of the septin family members in the regulation of synaptic function in relation to the pathogenesis of neurodegenerative diseases.
\end{abstract}

Keywords: Alzheimer's disease, Frontotemporal lobar degeneration, Huntington's disease long-term depression, Long-term potentiation, Neurodegeneration, Parkinson's disease, Septin, Synaptic dysfunction, Synaptic plasticity

\section{Introduction}

Impaired function and degeneration of synapses are among the earliest pathological alterations in neurodegenerative diseases. The exact molecular mechanisms that cause synaptic dysfunction in neurodegenerative diseases remain unclear, but significant efforts have been invested on understanding disease-related alterations in synaptic structure, function, and plasticity. Synaptic plasticity is generally divided into two main forms, long-term potentiation (LTP) and long-term depression (LTD). LTP is a process linked to learning and memory formation. In LTP, coinciding activation of both pre- and postsynaptic elements take place, leading to a long-lasting increase in synaptic transmission between the terminals and persistent

\footnotetext{
* Correspondence: mikko.hiltunen@uef.fi

${ }^{\dagger}$ Equal contributors

'Institute of Biomedicine, University of Eastern Finland, P.O. Box 1627, 70211

Kuopio, Finland

${ }^{2}$ Institute of Clinical Medicine - Neurology, University of Eastern Finland,

Kuopio, Finland

Full list of author information is available at the end of the article
}

strengthening of the synapse [1]. LTD, in turn, is a process depressing synaptic activity for a prolonged time. It is believed that in several neurodegenerative disorders, LTP is disrupted and LTD is promoted [2-4]. The most prominent forms of LTP and LTD are N-Methyl-D-aspartate receptor (NMDAR)-dependent. Different patterns of synaptic activation result in NMDAR activation, leading to induction of either LTP or LTD, through regulation of $\alpha$-amino-3-hydroxy-5-methyl-4-isoxazolepropionic acid receptor (AMPAR) localization at the postsynaptic terminal $[5,6]$. Overstimulation of extrasynaptic NMDAR is commonly noticed in neurological disorders, leading to an excess influx of calcium to the postsynaptic site, possibly promoting LTD and triggering various neurodegenerative events [7-9]. Also, observed variations in presynaptic and astrocyte activity have supported the idea for disease-related extrasynaptic NMDAR activation and LTP suppression $[10,11]$. Studying the relation between neurodegenerative disorders and alterations in synaptic plasticity is difficult due to that fact that the underlying 
mechanisms, which determine whether synaptic activation results in LTP or LTD, are not completely understood [6]. In addition, the neurodegenerative disease-associated mechanisms affecting the formation of LTP or LTD are thus far not clear. However, recent studies have identified several factors involved in neurodegenerative disorders, which may modulate synaptic plasticity, Although the understanding of synaptic function-related processes has recently leaped forward, unraveling the detailed mechanisms of synaptic function is essential for understanding the pathogenesis of neurodegenerative diseases at the molecular level. Recent studies have identified septin protein family members as possible candidates that take part in the regulation of synaptic processes and whose altered function might be involved in synaptic dysfunction in neurodegenerative diseases. Septins belong to a highly conserved family of guanosine-5'-triphosphate (GTP)-binding proteins, which play a role in the axonal transport, vesicular trafficking, and neurotransmitter release $[10,12]$. In addition, septins have been shown to interact with several key components related to neurological disorders (e.g. CDK5, XIAP/caspase-3, VAMP2, Parkin, and EAAT1). In this review, we will provide insights into synaptic dysfunction in neurodegenerative diseases, and how septins could play a role in the events leading to impaired synaptic function.

\section{Synaptic dysfunction in Alzheimer's disease}

Alzheimer's disease (AD) is the most common neurodegenerative disorder in the world, which affects up to $50 \%$ of individuals above the age of 85 . AD is clinically associated with a global cognitive decline and progressive loss of memory and reasoning. At autopsy, a large number of neuritic plaques and neurofibrillary tangles (NFT) in the neocortex of the brain are detected. These consist of amyloid- $\beta$ (A $\beta)$ peptide and hyperphosphorylated tau protein, respectively [13-16]. The $A \beta$ peptide is released from APP after sequential proteolytic cleavage by $\beta$ - and $\gamma$-secretases. The majority of APP is cleaved by $\alpha$-secretases, which leads to the release of the neuroprotective ectodomain portion of APP (sAPP $\alpha)$ and prevents $A \beta$ formation. Conversely, the cleavage of APP by $\beta$-secretase or BACE1 leads to the formation of the Nterminal secreted APP $\beta$ (SAPP $\beta$ ) and an APP C-terminal fragment (CTF) $\mathrm{C} 99$, which is consequently cleaved by $\gamma$-secretase producing $A \beta$ [17-20]. In $A D$, based on the prevailing amyloid cascade hypothesis, soluble $A \beta$ peptide levels are drastically increased, augmenting synaptic dysfunction, calcium dyshomeostasis, inflammation, oxidative stress as well as tau hyperphosphorylation and the formation of NFTs at specific brain regions in AD [21-23]. Synapses are considered the earliest site of pathology, and reduced synaptic activity is found to be the best pathological correlate of cognitive impairment in Alzheimer's disease [24]. Therefore, it is proposed in the amyloid cascade hypothesis, that accumulation of $\mathrm{A} \beta$ is an initial trigger for AD. Recent APP mutation studies support the notion that increased $A \beta$ production is a major factor causing AD. These studies identified a potential protective mutation in APP [25,26]. Substitution of alanine to threonine at position 673 in APP (A673T) was shown to decrease the production of $A \beta$ by 50 -fold [25]. Individuals with the mutation A673T on APP have decreased cognitive impairment due to aging and they score better in cognitive tests than those without the mutation. This raises the possibility that reduced $A \beta$ production throughout an individual's lifespan possibly has a protective effect against $\mathrm{AD}$ [25]. The exact molecular mechanisms of how $\mathrm{A} \beta$ accumulation initiates $\mathrm{AD}$ are unknown, and a focus has been set on unraveling the deleterious effects of excess $A \beta$ on synaptic function. Recent studies have shed light on a variety of pathways, which $A \beta$ synaptotoxicity is mediated through.

Despite the well-established foundation of the amyloid cascade hypothesis, the reported $\mathrm{A} \beta$-targeted trials in $\mathrm{AD}$ patients to date have not been successful [27]. Therefore, alternative therapeutic approaches focusing on other key events, such as the hyperphosphorylation and aggregation of tau have been actively explored. Recent findings show that the soluble forms of tau are synaptotoxic [28], which is comparable to that observed with soluble $A \beta$ oligomers $[8,29,30]$. Importantly, mislocalized tau in its hyperphosphorylated form has been shown to impair synaptic plasticity before the formation of NFTs [31,32]. However, failures in $A \beta$-targeted trials do not dismiss $A \beta$ as a key initiator in the synaptic dysfunction. Instead, the link between $A \beta$ and tau is evident as the oligomeric $A \beta$ causes the mislocalization of tau, leading to synaptic dysfunction $[31,32]$. This view is reinforced by findings in a mouse model with $\beta$-amyloid plaque deposition, in which behavioral impairments and excitotoxicity associated with $A \beta$ are reduced owing to a tau null background [33]. Recent findings by Ittner et al., also shed light to the possibility that hyperphosphorylated tau postsynaptically mediates the $A \beta$-induced toxicity, further emphasizing the reciprocal nature of the tau- and $A \beta$-mediated deleterious effects on synapses [32].

\section{$A \beta$-induced LTD activation via regulation of AMPAR localization}

The processing of APP through the amyloidogenic pathway is increased in $A D$, and toxic forms of $A \beta$ accumulate in the brain. Also, especially in the sporadic, late onset $\mathrm{AD}$ patients, decreased $A \beta$ clearance is centrally associated with the accumulation of $A \beta$ [34]. Concomitant to the increase in the toxic forms of $A \beta$, disturbances in signaling pathways mediated by caspase-3, Wnt, and GSK3 $\beta$ have been reported [35-38] (Figure 1). Many of these pathways 


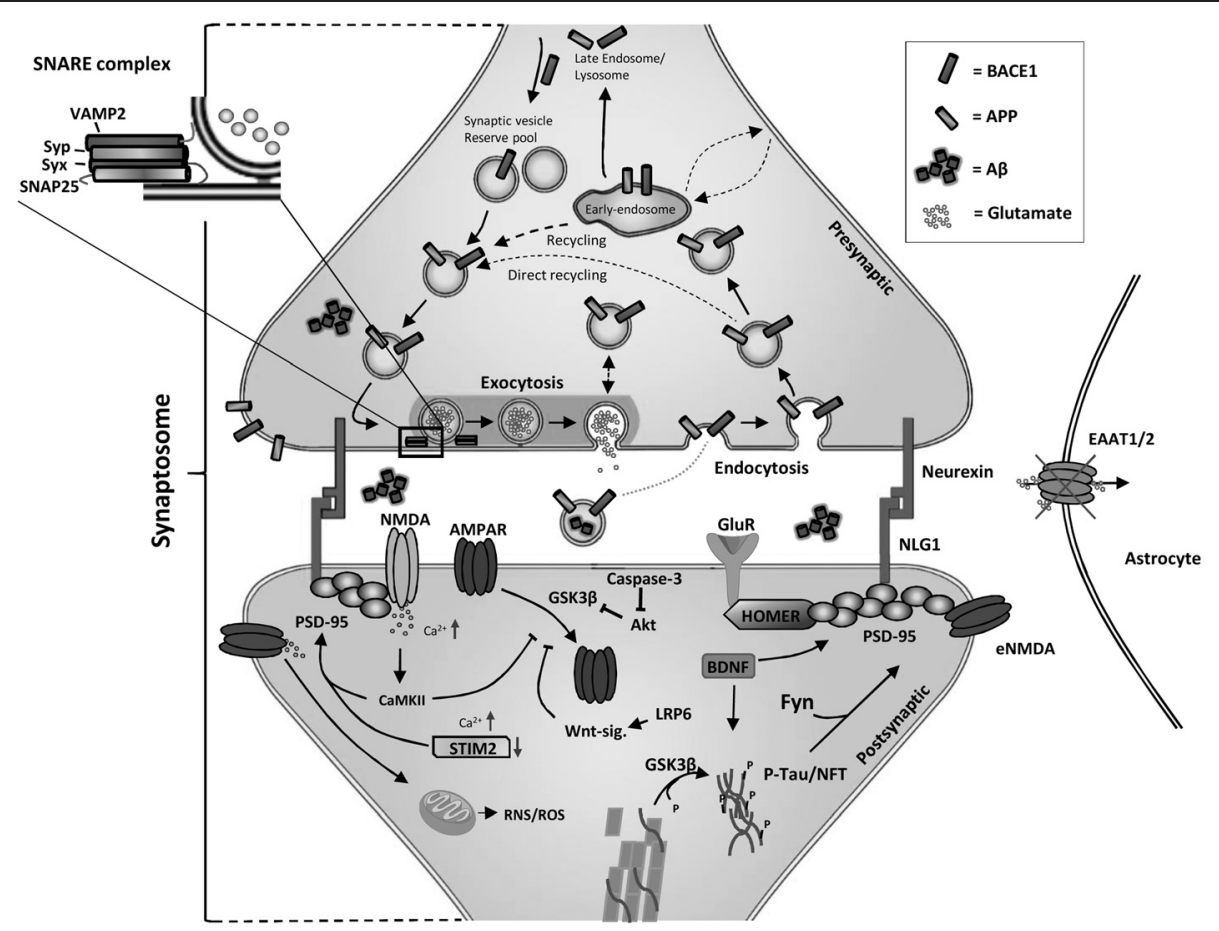

Figure 1 Schematic representation of specific synaptic alterations induced by excess accumulation of soluble $A \boldsymbol{B}$. $A \beta$ is produced from APP through sequential cleavages by BACE1 and $\gamma$-secretase at the presynaptic site and released to the synaptic cleft. Increased A $\beta$ accumulation results in the internalization of AMPAR from the postsynaptic membrane, possibly via caspase-3-Akt1-GSK3 3 or altered LRP6-mediated Wnt signaling. A $\beta$ may induce activation of extrasynaptic NMDAR (eNMDAR), due to faulty EAAT1/2-mediated regulation of glutamate levels by astrocytes, leading to the activation induction of downstream RNS/ROS-mediated neurodegenerative events. Additionally, $A \beta$ accumulation induces tau localization to postsynaptic sites, resulting in the postsynaptic recruitment of Src kinase Fyn. A $\beta$ is also proposed to activate histone deacetylase 2, resulting in the suppressed expression of genes required for synaptic function and stability, such as BDNF, Cdk5, Homer1, NLGN1, Syp, GluR1, GluR2, NR2A, NR2B, and STIM2. Abbreviations: Brain-derived neurotrophic factor (BDNF), Cyclin-dependent kinase 5 (CDK5), Homer homolog 1 (Homer1), Neuroligin 1 (NLGN1), Synaptophysin (Syp), Glutamate receptor 1 (GluR1), Glutamate receptor 2 (GluR2), N-mehtyl-D-Aspartate 2A (NR2A), N-mehtyl-D-Aspartate 2B (NR2B), Stromal interaction molecule 2 (STIM2).

suggest that $\mathrm{AD}$ may represent a form of metabolic disease in the brain with resistance or deficiency of brain insulin and insulin-like growth factor-1 [39-41]. GSK3 $\beta$ is a wellknown player in $\mathrm{AD}$, strongly associated with the formation of NFTs via hyperphosphorylation of tau. Recently, GSK3 $\beta$ has also been linked to AMPAR trafficking and synaptic plasticity and it is a necessary component for LTD induction [38] (Figure 1). During the induction of LTD, GSK3 $\beta$ is activated by protein phosphatase 1 via dephosphorylation of GSK3 $\beta$ Ser9 [38]. Active GSK3 $\beta$ is known to co-localize with AMPAR, implying that it regulates the trafficking of AMPAR from the postsynaptic membrane [38]. On the other hand, caspase-3 may cleave Akt1, rendering Akt1 incapable of inhibiting GSK3 $\beta$ activation [36]. In the presence of $A \beta$, caspase- 3 is activated and it cleaves Akt 1 . This allows the activation of GSK $3 \beta$ by PP 1 , and possibly the subsequent removal of AMPARs from the postsynaptic membrane, resulting in LTD induction [36] (Figure 1).

$\mathrm{A} \beta$-induced synaptic dysfunction can also be mediated via impairment of the Wnt signaling pathway (Figure 1). Wnt signaling takes part in the modulation of several neuronal processes, such as neurotransmitter release at the presynaptic terminal, glutamate receptor trafficking and interactions with postsynaptic density protein 95 (PSD-95), which are the key components in LTP and LTD [42,43]. Recently Liu et al., 2014 [29] focused on the relationship between Wnt signaling and AD. They found that low-density lipoprotein receptor-related protein 6 (LRP6)-mediated Wnt signaling is downregulated in post-mortem $\mathrm{AD}$ brains and that it negatively correlates with $A \beta$ levels. Reduced LRP6-mediated Wnt signaling may not only lead to synaptic dysfunction, but also to an increase in the amyloidogenic processing of APP, creating a vicious cycle between increased production of $A \beta$ and decreased LRP6-mediated Wnt signaling in AD pathogenesis [37]. The exact molecular mechanisms related to synaptic dysfunction due to the decrease in LRP6-mediated Wnt signaling is not known, but it can be hypothesized that LRP6 could be a relevant factor for the maintenance of glutamate receptors at the postsynaptic membrane and thus induction of LTP $[37,42,43]$. 


\section{A $\beta$-induced overstimulation of extrasynaptic NMDAR}

It has been suggested that LTP disruption in AD could also be mediated through $A \beta$-induced overstimulation of extrasynaptic NMDAR, due to impaired regulation of glutamate levels (Figure 1). This may lead to calcium dyshomeostasis and different redox events [7,11,23,44]. In $\mathrm{AD}$, glutamate transporters EAAT1 and EAAT2, which are responsible for glutamate uptake in glial cells, are downregulated in the brain of AD patients [43]. This results in excess accumulation of glutamate to the synaptic cleft, and overstimulation of NMDAR. Increased A $\beta$ levels have also been shown to cause astrocyte-mediated glutamate release, which can further exacerbate the excitotoxicity [11] (Figure 1). Ultimately, overstimulation of NMDAR triggers various translational and post-translational modifications in a vast set of proteins, resulting in the activation of downstream pathological events $[7,45]$. Supporting the relevance of NMDAR overstimulation in AD, a partial NMDAR antagonist, which blocks the NMDA overstimulation, has been shown to be neuroprotective in various animal models and to alleviate both neurodegenerative and vascular processes [46-48]. Memantine, a partial NMDAR blocker is also used as a treatment for AD patients and it has a beneficial impact in Parkinson's disease (PD) patients. Unfortunately, memantine only provides short-term relief, indicating that there are several underlying mechanisms contributing to synaptic dysfunction in these disorders [49-51].

\section{Mislocated tau mediates AD-related synaptic deficiency}

Tau has recently been identified as a mediator of $A \beta$-related excitotoxicity [32]. Tau is a microtubulestabilizing axonal protein, but it is also known to function in the dendritic compartments with a pivotal role in postsynaptic plasticity $[31,32,52]$. At resting-state, tau is widely spread throughout the dendrites from where it is transported to postsynaptic sites upon synaptic activation. Activity-dependent tau translocation simultaneously induces an increase in LTP-related molecular components, such as PSD-95, glutamate receptor subunit GluR1, and Fyn, at the postsynaptic site [31]. Moreover, augmented $A \beta$ levels have been shown to increase the localization of tau to postsynaptic sites during the resting-state and to disrupt the recruitment of PSD-95 and GluR1 during synaptic activation [31]. These results collectively suggest that tau is an important functional constituent sustaining LTP. This concept is in line with the findings showing $A \beta$ related reduction in LTP activation [53]. The abnormal localization of tau has been especially observed in mice expressing the full-length P301L mutant of tau [32,54]. Due to the aberrant resting-state localization, tau is likely able to enhance $A \beta$-related excitotoxicity by promoting the localization of the Src kinase Fyn to the postsynaptic sites [32]. Fyn is responsible for the phosphorylation of
NMDAR subunit 2B (NR2B), which again facilitates the interaction between NR2B and PSD-95 [55,56]. Disruption of the NR2B/PSD-95 complex has been shown to prevent the excitotoxic effects of $A \beta$, suggesting that tau-dependent Fyn localization to the postsynaptic site plays a key role in A $\beta$-related synaptic dysfunction [32,57]. Furthermore, the fact that APP23/tau ${ }^{-/-}$mice show significantly reduced premature mortality and susceptibility to $A \beta$-related excitotoxicity as compared to APP23 mice provides further support for the idea that tau mediates $A \beta$-related excitoxicity. Conversely, APP23 mice expressing the full-length P301L mutant tau show increased premature mortality [32]. Collectively, these findings highlight tau as a plausible target for intervention in $\mathrm{AD}$ apart from $\mathrm{A} \beta$.

\section{Epigenetic changes in synaptic plasticity-related genes in Alzheimer's disease}

Other possible pathogenic mechanisms by which $A \beta$ accumulation may cause synaptic dysfunction in $A D$ are epigenetic alterations. Recent findings show that $A \beta$ induces epigenetic changes via an increase in histone deacetylase 2 (HDAC2) levels, leading to decreased expression of Arc, BDNF, Cdk5, Erg1, Homer1, NLGN1, Syp, GluR1, GluR2, Nfl, NR2A, NR2B, STIM2, and Syt1 [58]. These are essential presynaptic and postsynaptic components for synaptic plasticity (Figure 1) [6,59-62]. It has been observed that RNA interference (RNAi)-mediated reduction of HDAC2 levels in p25 overexpressing mice results in rescued synaptic morphology and plasticity. The reduction of HDAC2 in p25 overexpressing mice also results in the alleviation of cognitive and memory functions [58]. To further prove the relevance of HDAC2 in AD, postmortem samples of AD brain were analyzed to show that HDAC2 accumulation was evident already at early stages of the disease progression [58]. This further underscores the notion that there are several underlying mechanisms contributing to synaptic dysfunction in neurodegenerative diseases.

The above-mentioned factors and pathways are only some of which may mediate $A \beta$-induced synaptic dysfunction. Several other factors, which are essential for synaptic function and possibly affected by $A \beta$, such as PSD-95, $\alpha 7 \mathrm{nAChR}, \operatorname{PrP}^{\mathrm{c}}$, have also been identified. This indicates that $A \beta$ may induce synaptic dysfunction in $A D$ via a very complex combination of different mechanisms [63-65]. Further studies are needed for a complete understanding of the complex array of different pathways regulating synaptic function in health and disease.

\section{Altered synaptic plasticity in Parkinson's disease}

AD-related synaptic dysfunction has been widely studied as it is clearly connected to neurodegeneration and brain atrophy in AD patients. However, dysfunction and degeneration of synapses is a common hallmark of also 
other neurodegenerative disorders, such as Parkinson's disease (PD), Huntington's disease (HD), and frontotemporal lobar degeneration (FTLD) [66-69]. PD is a progressive, debilitating neurodegenerative disorder characterized by deterioration of motor capacities, and in some cases, dementia [70]. The main clinical hallmarks of PD are progressive loss of substantia nigra pars compacta neurons and formation of Lewy bodies/neurites in the substantia nigra, the brain stem and the cerebral cortex. A subset of PD cases are caused by mutations in genes, such as $\alpha$ synuclein, parkin, and LRRK2 [71-73]. A decrease in LTP activation has been shown in PD models. There is also evidence that treatment with a dopamine precursor alleviates the reduced LTP $[3,68]$. The underlying cause for the reduced LTP remains elusive, but a relationship between the above mentioned genetic determinants and presynaptic function has been suggested. Mutated $\alpha-$ synuclein, a main component of Lewy bodies found in post-mortem PD brain, is known to localize to presynaptic terminals and may negatively impact synaptic vesicle (SV) docking and release [10,74,75]. Burre et al., 2010 [61] showed that $\alpha$-synuclein interacts with vesicleassociated membrane protein 2 (VAMP2), a N-ethylmaleimide-sensitive fusion protein receptor (SNARE) complex protein, and stabilizes the SNARE complex during synaptic activity. This agrees with the findings that mutations in $\alpha$-synuclein lead to toxic effects and result in reduced neurotransmitter release in hippocampal pyramidal neurons [10]. Furthermore, overexpression of mutated $\alpha$-synuclein decreases the levels of synapsin and complexin 2 , corroborating the idea that $\alpha$-synuclein mutations lead to impaired SV release [10]. Also, co-immunoprecipitation of $\mathrm{Rab} 3 \mathrm{~A}$ and the A30P $\alpha$-synuclein mutant implicate a link between SVs and $\alpha$-synuclein $[76,77]$. LRRK2, another important player in $\mathrm{PD}$, has also been hypothesized to regulate SV recycling, but through endocytic processes [78-80]. LRRK2 is suggested to colocalize with Rab5b and thus alter endocytic vesicular transport, suggesting that LRRK2 may affect SV trafficking [79]. Several findings support the notion that LRRK2 alters endocytosis and overexpression of LRRK2 has been shown to suppress SV endocytosis in mouse primary hippocampal neurons [80]. These data altogether suggest that deficient synaptic function plays an important role in the pathogenesis of PD.

\section{Alterations in synaptic activity in Huntington's disease and frontotemporal lobar degeneration}

Altered synaptic plasticity may also be involved in the pathogenesis of $\mathrm{HD}$, a neurodegenerative disorder causing motor dysfunction, psychiatric symptoms, and cognitive decline $[81,82]$. Evidence shows that impairment of LTP is evident in HD $[2,69]$. It has been suggested that increased glutamate release associated with this disease results in the overexcitement of post-synaptic glutamate receptors [69]. HD is caused by the expansion of a CAG repeat in the $H t t$ gene, which leads to the aggregation of $\mathrm{Htt}$ protein to the nucleus and cytoplasm of cells. This has toxic effects and eventually leads to cell death [82]. The mechanisms by which the Htt mutation causes neurodegeneration remain so far elusive. However, altered neuronal activity can be initially noticed in the cortex and striatum of HD brain, from where it further spreads to other brain areas and leads to neuronal degeneration [82]. As mentioned above, an increase in glutamate release is apparent at the early stages of $\mathrm{HD}$, and this eventually results in the loss of glutamatergic terminals. A reduction in astrocyte glutamate transporter 1 (GLT1) levels is commonly observed in HD rodent models, which could contribute to the accumulation of excess glutamate [83-85]. Excess glutamate will most likely lead to stimulation of extrasynaptic NMDAR, leading to the activation of downstream neurodegenerative events [86]. Supporting this notion, extrasynaptic NMDAR expression and signaling are increased in acute brain slices and corticostriatal cultures from the HD mouse model YAC128. Moreover, clinical studies have indicated that the partial NMDAR blocker memantine has beneficial effects in HD patients [87].

Studies of synaptic alterations in FTLD have been so far limited. FTLD is heterogeneous group of clinical syndromes, which leads to dementia and primarily affects the frontal and temporal lobes of the brain [81]. Evidence for synapse loss and a decrease in synaptic density in FTLD brains implicates that synaptic dysfunction may also underlie the pathogenesis of this disease entity [88-90], but no clear explanation for these synaptic alterations have been found. Alterations in synaptic proteins are also evident at specific layers of the frontal cortex in FTLD brain, pointing towards the possibility that a decrease in synaptic activity could underlie the clinical outcome [67]. In conclusion, eminent data implicate that altered synaptic function is centrally involved in the early pathogenesis of the different neurodegenerative diseases. Although diverse brain regions are specifically affected in each of these diseases, the current data suggest that common molecular mechanisms leading to synaptic dysfunction may underlie disease pathogenesis. Therefore, characterization of factors and pathways, which regulate synaptic function, is essential and may lead to the discovery of novel therapeutic targets.

\section{The Septin protein family}

Alterations in the functions of neuronal cells is evident in neurodegenerative diseases. Especially, changes in the synaptic plasticity during early phases of these diseases have been suggested to lead to the activation of neurodegenerative events. The complexity of the mechanisms of 
synaptic plasticity complicates the understanding how these processes are altered in different disorders. However, understanding the mechanisms leading to deficient function and degeneration of synapses is essential for a better comprehension of the pathogenesis of neurodegenerative diseases in general. One of the potential candidates regulating synaptic function is the septin protein family.

Septins are a highly conserved family of GTP-binding proteins [91,92]. In mammals, there are 13 known septins, which are divided in to four subgroups; SEPT2 (Septin 1, 2, 4, 5), SEPT3 (Septin 3, 9, 12), SEPT6 (Septin 6, 8, 10, 11, 14), and SEPT7 (Septin 7) [12]. The septin protein family members are highly expressed in the brain, and are known to take part in processes such as regulation of formation, growth and stability of axons and dendrites, synaptic plasticity, and vesicular trafficking [12,92-96]. In addition to these physiological functions, septins have been linked to different neurodegenerative and psychiatric disorders, such as PD, AD, and schizophrenia [97-99]. The septins are 30-65-kDa proteins, and they share a common central GTP-binding domain, 53 highly conserved amino acids known as the septin unique element (SUE) at the $\mathrm{C}$-terminus, and a polybasic region located at the immediate N-terminus (Figure 2). The GTP-binding domain consists of the conserved $\alpha-\beta$ core, built up by interacting $\alpha$-helices and $\beta$-strands, and the loop elements, which take part in the binding of GTP and its possible hydrolysis to guanosine diphosphate (GDP). The GTP-binding domain also contains two $\alpha$-helical elements at the ends of the conserved core and two insertions, one $\alpha$-helix and one $\beta$-hairpin, in the GTPase core [100-102]. This domain mediates the formation of septin filaments and interactions with various other proteins. The neighboring polybasic region is believed to assist the GTP-binding domain in associations with other septins and is capable of directly binding to the phosphoinositides on the plasma membrane. The functions of the neighboring SUE are so far unknown. The rest of the protein is composed of varying $\mathrm{N}$ - and $\mathrm{C}$-terminal regions, which may contain a proline-rich domain and an $\alpha$-helical coiled-coil domain, respectively. Many of the septins possess $\alpha$ helical extension at their $\mathrm{N}$ - and $\mathrm{C}$-termini. The $\mathrm{N}$ - and C-terminal regions also play a vital role in septin interactions $[91,103,104]$.

The role of GTP and GDP in the function and assembly of septin filaments is still fairly poorly known. Evidence shows that the presence of GTP regulates the positions of structural motifs in the GTP-binding domain called switches. The different conformational changes caused by the GTP/GDP molecules are believed to be required for the formation of stable septin complexes and the dissociation of the complexes during different phases of the cell cycle [105]. These conformational changes are also transmitted through to the $\mathrm{N}$-terminal helix affecting the septin-septin interactions. Therefore septins subgroup SEPT6 (SEPT6, 8, 10, 11, and 14) lack a threonine residue (T78*), which is needed for the hydrolyzation of GTP to GDP [105]. This feature is necessary for the formation of certain complexes, such as the SEPT26-7 trimeric filament, where GTP can stabilize the SEPT2-6 GTP-binding domain interaction (G-dimer), without affecting the SEPT6-7 $\mathrm{N}$ - and C-termini interaction (NC-dimer) [100] (Figure 2). A further role in the formation, localization and function of septin complexes has been hypothesized for GTP and GDP. No direct evidence for this has been found, but mutations in residues at the GTP-binding site have been shown to alter these features [101].

\section{Septins in neurodegenerative disease-related synaptic processes}

The septin family provides several interesting candidates possibly involved in the underlying mechanisms of synaptic dysfunction and neurodegeneration in neurodegenerative diseases. Septins have been shown to associate with AD, PD, HD, FTLD, and Down syndrome [98,99,106-111], suggesting that septins are involved in the pathogenic mechanisms of different neurodegenerative diseases. Related to this, a recent study on the brain proteome revealed that SEPT2/3 levels were increased, while SEPT5 levels were decreased in the temporal neocortex of AD patients as compared to non-AD subjects [112]. Also, genetic characterization of SEPT3 gene identified a polymorphic site at the exon 11, which significantly associated with $\mathrm{AD}$ in a case-control study [113]. Moreover, studies in the frontal cortex homogenates of FTLD-U patients have shown an increase in the truncated forms of SEPT11 ( $\sim 5 \mathrm{kDa}, \sim 37 \mathrm{kDa}$, and $\sim 28 \mathrm{kDa})$ and the presence of fibrillar thread-like structures of SEPT11, which were specifically localized to the superficial cortical layers [108]. The pathological functions of these thread-like structures remain elusive, but based on the known localization of SEPT11 to microtubules and stress fibers, it can be hypothesized that formation of these structures could disrupt cytoskeletal functions and result in cellular toxicity $[114,115]$. In the context of HD, a significant down-regulation of SEPT4 was detected in cells expressing mutated huntingtin [116].

The diverse interactome of septins suggests that they have an essential role in vesicle trafficking, which may be key for e.g. sufficient neurotransmitter release. SEPT8 has been shown to interact with components, such as VAMP2 and syntaxin-1 of the SNARE complex. SEPT8 possibly promotes the release of VAMP2 from synaptophysin during action potential stimulation, allowing the formation of the SNARE complex and subsequently enhanced docking of vesicles to the presynaptic membrane 


\section{A}

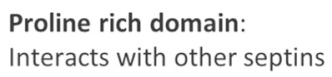

Proline rich domain:

Interacts with other septins

GTP-binding domain: Interacts with septins, other proteins, and

the plasma membrane Coiled-Coil: Interacts with other septins
$\mathrm{N}$

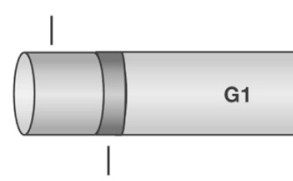

Polybasic region: Assists the GTP-binding domain in septin and plasma membrane interations

B

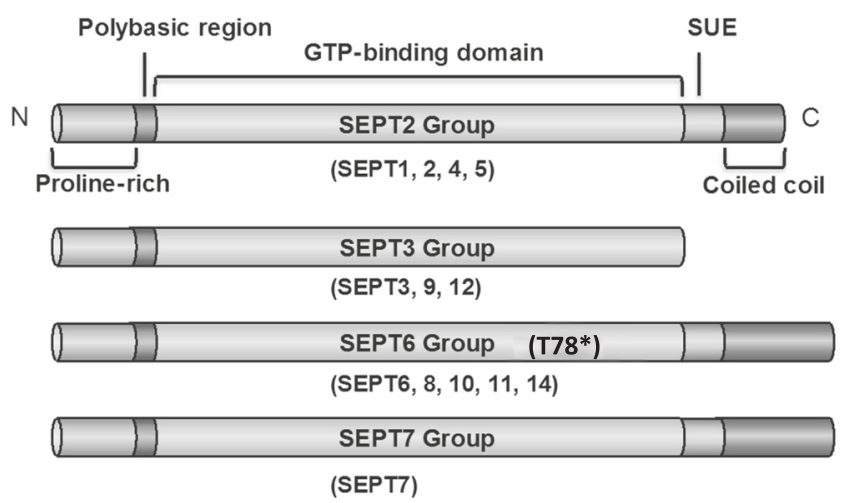

C

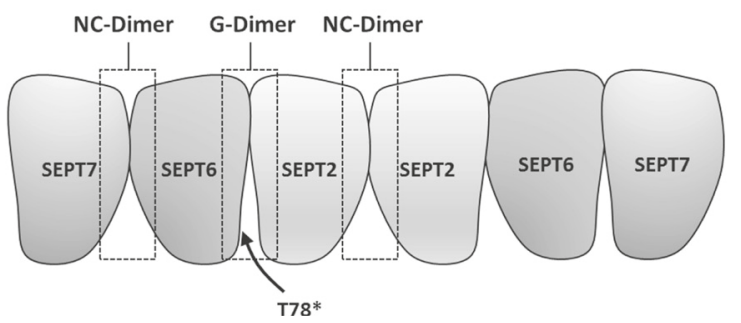

Figure 2 Schematic showing the common structure of septin protein family and the structures of individual septin subgroups. A. The septin protein structure consists of a GTP-binding domain composed of conserved motifs G1 (GxxxxGK[S/T]), G3 (DxxG) and the GTP-specificity motif $G 4$ (xKxD). D, G, K, S, and T represent aspartic acid, glycine, lysine, serine, and threonine residues, respectively, and $x$ indicates any amino acid. The N-terminus consists of a proline-rich domain and a polybasic region. The C-terminus contains a septin unique element (SUE) and a varying a-helical coiled-coil domain. B. Based on sequence homology and domain composition, the 13 septins have been divided in to four subgroups (SEPT2, SEPT3, SEPT6, and SEPT7). Septins of subgroup SEPT6 lack a threonine residue (T78*), which is needed for the hydrolyzation of GTP to GDP. C. The formation of septin filaments mediated by the interaction between GTP-binding domains (G-dimer) and the N-and C-termini containing faces (NC-dimer). Formation of septin filament structures require different conformational changes mediated by the GTP/GDP molecules, allowing the assembly and disassembly of stable septin complexes. These conformational changes are also influencing the $\mathrm{N}$-terminal helix and thus affect the formation of the NC-dimer. Therefore, the lack of a threonine residue $\left(T 78^{*}\right)$, resulting in the inability of the septin protein to hydrolyze GTP to GDP, enables the formation of e.g. SEPT2-6-7 complex.

[94] (Figure 3). Conversely, SEPT5 has been suggested to negatively regulate SV release at inhibitory presynaptic terminals by forming filamentous barricades at the presynaptic membrane [92]. SEPT5 has also been shown to interact with syntaxin-1, resulting in decreased exocytosis [117,118] (Figure 3). SEPT5-syntaxin-1 interaction and the formation of filamentous barricades is considered to be regulated by the CDK5-mediated changes in SEPT5 phosphorylation status [93]. CDK5 is able to phosphorylate SEPT5 at serine 161 (S161) and
327 (S327). Blocking the phosphorylation of SEPT5 at these sites resulted in enhanced binding of SEPT5 to syntaxin-1 in PC12 cells [93]. The activity of CDK5 is deregulated in AD [119]. This could result in altered SEPT5 phosphorylation and exocytosis at inhibitory presynaptic terminals, and thus possibly contribute to altered synaptic activity in AD. Parkin 2 (PARK2), an E3-ubiquitin ligase, has been identified as another possible modulator of SEPT5-syntaxin-1 interaction. Interestingly, mutations in $P A R K 2$ are responsible for autosomal 


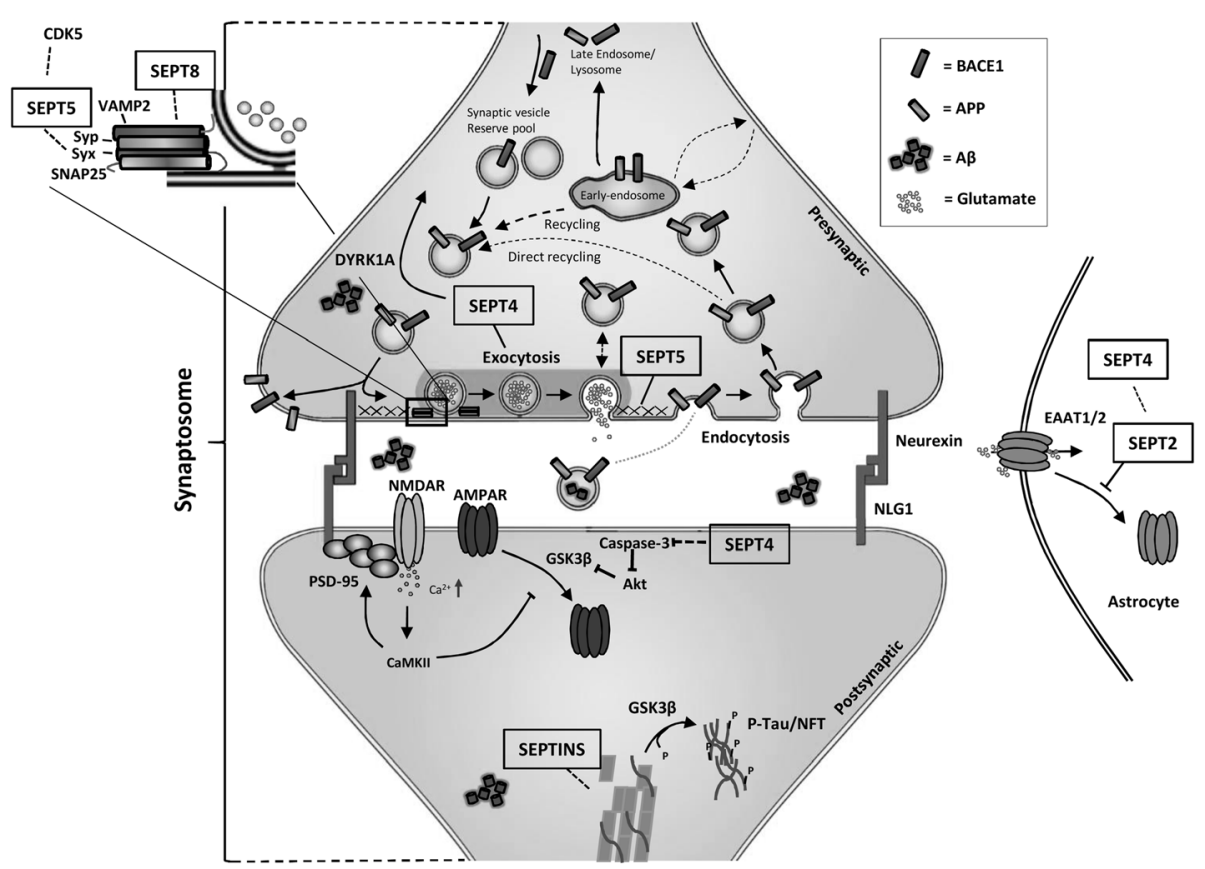

Figure 3 The possible roles of septins in synaptic plasticity and mechanisms of neurodegeneration. SEPT4, SEPT5 and SEPT8 have been hypothesized to control synaptic vesicle trafficking at the presynaptic terminal by interacting with different components of the SNARE complex and regulating synaptic vesicle localization at the presynaptic membrane. Also SEPT2 and SEPT4 may regulate neurotransmitter levels at the synapse by regulating glutamate transporter localization in astrocytes. Additionally, SEPT4 may affect caspase-3 activity. SEPT4 functions are possibly regulated by DYRK1A-mediated phosphorylation. Septins also are known to interact with actin and microtubules, suggesting that they may affect tau. SEPT1, 2, and 4 have been found to localize in in NFTs.

recessive early-onset PD and a subset of sporadic PD [71]. PARK2 ubiquitinates SEPT5, which leads to the degradation of SEPT5, enabling the release of syntaxin-1 to enhance SV docking [111]. This agrees with the idea that PD-associated reduction in parkin results in the accumulation of SEPT5 and subsequent neuronal toxicity in dopaminergic neurons $[107,120]$.

The fact that SEPT1, 2, and 4 have been found in NFTs provides further confirmation that different septin family members are associated with neurological diseases $[98,110]$. SEPT2 is involved in synaptic plasticity and has been found to interact with the glutamate transporter EAAT1 and regulate its cellular localization (Figure 3). SEPT2 binding to EAAT1 is GDP-dependent and GDPbound SEPT2 is capable of binding to and internalizing EAAT1. GDP binding to septins is considered to disrupt the formation of septin filaments and thus it is hypothesized that the GTP-bound form of SEPT2 is capable of forming septin filaments and stabilizing EAAT1 at the cell surface $[100,121]$. The absence of EAAT1 from the cell surface could lead to the increased levels of glutamate in the extracellular space and possibly overstimulation of NMDAR [121] (Figure 3). Co-immunoprecipitation studies of SEPT2 and EAAT1 have revealed that also SEPT4 interacts with EAAT1, which points to a possible formation of heteromeric complexes between SEPT2 and
SEPT4 [121]. In addition to the co-localization with NFTs and EAAT1, SEPT4 has been linked to PD and Down syndrome through interaction with parkin and DYRK1A (dual-specificity tyrosine phosphorylation-regulated kinase 1A) $[106,122]$. DYRK1A levels are known to be increased in Down syndrome patients and it has been shown to phosphorylate SEPT4 at S68 and S107. The direct impact of this phosphorylation is elusive, but DYRK1A also phosphorylates $\alpha$-synuclein, which is another interacting partner of SEPT4 [122]. Since $\alpha$-synuclein is the key component of PD-related Lewy bodies, the DYRK1Amediated phosphorylation of SEPT4 may be associated with the formation of Lewy bodies [109,122]. Loss of SEPT4 in dopaminergic neurons has been observed in the sporadic PD patients, which could be due to the sequestration of SEPT4 into $\alpha$-synuclein aggregates and neuronal loss $[109,123]$. The loss of SEPT4 also results in diminished dopaminergic neurotransmission, suggesting that SEPT4 may play a central role in dopamine release and reuptake in the presynaptic machinery [109]. SEPT4, similarly to SEPT5, is also a substrate for parkin, emphasizing further the potential importance of SEPT4 in the pathogenesis of PD [106]. Furthermore, SEPT4 may be involved in AD based on its interactions with X-linked inhibitor of apoptosis protein, a regulator of caspase-3 activity [124,125] (Figure 3). 
Overall, considering the localization of septins in neurons, their involvement in the regulation of synaptic functions, and their other known interactions, septins may prove as central candidates involved in the pathogenic mechanisms of various neurological diseases. However, further studies are need to comprehensively understand septin functions and the outcomes of septin interactions. A focus should also be set on understanding the effects of septin-septin interactions, because they are known to form various hetero- and homomeric structures, which have regulatory and compensatory effects on neuronal functions [104]. Recent findings by Tokhtaeva et al. further emphasize the importance of studying septin-septin interactions, since disabling the formation of heteromeric septin oligomers impairs the exocytosis of proteins and neurotransmitters [126]. It was also shown that septins undergo constant reassembly at different phases of vesicle recycling, supporting their role in the various steps related to neurotransmitter release and uptake [126].

\section{Conclusion}

The underlying mechanisms in different neurodegenerative disorders have remained elusive. However, increasing evidence suggests that abnormal synaptic activity and synaptic dysfunction are common in different neurodegenerative diseases and may in fact represent some of the earliest pathogenic alterations during their pathogenesis. In agreement with this notion, recent studies have shown that changes in the expression levels of specific synaptic proteins in the cerebrospinal fluid reflect degeneration of synapses and can be successfully used to predict $\mathrm{AD}$ patients and evaluate $\mathrm{MCI}$-to-AD conversion at very early stages of the disease $[127,128]$. The observation that the protein levels of different septins are altered in AD patients [114] suggests that also septins could represent early markers linked to synaptic dysfunction and synaptoxicity. Alterations in the expression levels, phosphorylation status, and subcellular localization of various pre- and postsynaptic proteins in neurodegenerative diseases emphasize that extremely complex mechanisms are likely to be involved in the etiology of these diseases. Therefore, further research is needed to unravel the specific mechanisms by which synaptic plasticity is affected in neurodegenerative diseases. Thus, it is plausible that novel disease biomarkers and therapeutic targets will be identified through more detailed characterization of the aberrant changes in synaptic plasticity-related factors and pathways at different phases during the progression of these diseases [129]. This may require identification of new candidates, which are involved in the regulation of synaptic plasticity and neurodegenerative diseaserelated mechanisms. Septin protein family, implicated in the regulation of several different aspects of synaptic vesicle trafficking and neurotransmitter release, may offer such novel candidates for further assessments in the pathogenesis of neurodegenerative diseases. Therefore, the future studies should focus on better understanding of the functions, regulation, and interactomes of different septin family members in health and disease.

\section{Abbreviations}

AD: Alzheimer's disease; AMPAR: AMPA receptor; APP: Amyloid precursor protein; $A \beta$ : Amyloid- $\beta$; BDNF: Brain-derived neurotrophic factor; CDK5: Cyclin-dependent kinase 5; DYRK1A: Dual-specificity tyrosine phosphorylation-regulated kinase 1A; FTLD: Frontotemporal lobar degeneration; GluR1: Glutamate receptor 1; GluR2: Glutamate receptor 2; GLT1: Glutamate transporter 1; GDP: Guanosine diphosphate; GTP: Guanosine triphosphate; HDAC2: Histone deacetylase 2; Homer1: Homer homolog 1; HD: Huntington's disease; LTD: Long term depression; LTP: Long-term potentiation; LRP6: Low-density lipoprotein receptor-related protein 6; SNARE: N-ethylmaleimide sensitive fusion protein receptor; NR2A: N-mehtyl-D-Aspartate 2A; NR2B: N-mehtyl-D-Aspartate 2B; STIM2: Stromal interaction molecule 2; Syp: Synaptophysin; NFT: Neurofibrillary tangles; NLGN1: Neuroligin 1; NMDAR: NMDA receptor; PARK2: Parkin 2;

PD: Parkinson's disease; RNAi: RNA interference; SUE: Septin unique element; SV: Synaptic vesicle; VAMP2: Vesicle-associated membrane protein 2.

\section{Competing interests}

The authors declare that they have no competing interests.

\section{Authors' contributions}

MM wrote the manuscript. $\mathrm{AH}$ and $\mathrm{MH}$ revised the manuscript. All authors have read and approved the final manuscript.

\section{Acknowledgements}

This study was supported by grants from the Academy of Finland, VTR grant of Kuopio University Hospital; the Strategic Funding of the University on Eastern Finland (UEF-Brain); Sigrid Juselius Foundation; FP7, Grant Agreement no 601055, and VPH Dementia Research Enabled by ITVPH-DARE@IT.

\section{Author details}

${ }^{1}$ Institute of Biomedicine, University of Eastern Finland, P.O. Box 1627, 70211 Kuopio, Finland. ${ }^{2}$ Institute of Clinical Medicine - Neurology, University of Eastern Finland, Kuopio, Finland. ${ }^{3}$ Department of Neurology, Kuopio University Hospital, Kuopio, Finland.

Received: 15 December 2014 Accepted: 23 March 2015 Published online: 03 April 2015

\section{References}

1. Cooke SF, Bliss TV. Plasticity in the human central nervous system. Brain. 2006;129:1659-73.

2. Eidelberg D, Surmeier DJ. Brain networks in Huntington disease. J Clin Invest. 2011;121:484-92.

3. Goldberg MS, Pisani A, Haburcak M, Vortherms TA, Kitada T, Costa C, et al. Nigrostriatal dopaminergic deficits and hypokinesia caused by inactivation of the familial Parkinsonism-linked gene DJ-1. Neuron. 2005;45:489-96.

4. Li S, Hong S, Shepardson NE, Walsh DM, Shankar GM, Selkoe D. Soluble oligomers of amyloid Beta protein facilitate hippocampal long-term depression by disrupting neuronal glutamate uptake. Neuron. 2009;62:788-801.

5. Oh MC, Derkach VA, Guire ES, Soderling TR. Extrasynaptic membrane trafficking regulated by GluR1 serine 845 phosphorylation primes AMPA receptors for long-term potentiation. J Biol Chem. 2006;281:752-8.

6. Malenka RC, Bear MF. LTP and LTD: an embarrassment of riches. Neuron. 2004;44:5-21.

7. Hardingham GE, Bading H. Synaptic versus extrasynaptic NMDA receptor signalling: implications for neurodegenerative disorders. Nat Rev Neurosci. 2010;11:682-96.

8. Shankar GM, Bloodgood BL, Townsend M, Walsh DM, Selkoe DJ, Sabatini BL. Natural oligomers of the Alzheimer amyloid-beta protein induce reversible synapse loss by modulating an NMDA-type glutamate receptor-dependent signaling pathway. J Neurosci. 2007;27:2866-75.

9. Minano-Molina AJ, Espana J, Martin E, Barneda-Zahonero B, Fado R, Sole M, et al. Soluble oligomers of amyloid-beta peptide disrupt membrane 
trafficking of alpha-amino-3-hydroxy-5-methylisoxazole-4-propionic acid receptor contributing to early synapse dysfunction. J Biol Chem. 2011;286:27311-21.

10. Nemani VM, Lu W, Berge V, Nakamura K, Onoa B, Lee MK, et al. Increased expression of alpha-synuclein reduces neurotransmitter release by inhibiting synaptic vesicle reclustering after endocytosis. Neuron. 2010;65:66-79.

11. Talantova M, Sanz-Blasco S, Zhang X, Xia P, Akhtar MW, Okamoto S, et al. Abeta induces astrocytic glutamate release, extrasynaptic NMDA receptor activation, and synaptic loss. Proc Natl Acad Sci U S A. 2013;110:E2518-27.

12. Hall PA, Russell SE. The pathobiology of the septin gene family. J Pathol. 2004;204:489-505.

13. Cummings JL. Alzheimer's disease. N Engl J Med. 2004;351:56-67.

14. DeKosky ST, Scheff SW. Synapse loss in frontal cortex biopsies in Alzheimer's disease: correlation with cognitive severity. Ann Neurol. 1990;27:457-64.

15. Mandelkow EM, Mandelkow E. Tau in Alzheimer's disease. Trends Cell Biol. 1998:8:425-7.

16. Neve RL, McPhie DL, Chen Y. Alzheimer's disease: a dysfunction of the amyloid precursor protein(1). Brain Res. 2000;886:54-66.

17. De Strooper B. Proteases and proteolysis in Alzheimer disease: a multifactorial view on the disease process. Physiol Rev. 2010;90:465-94.

18. Vetrivel KS, Thinakaran G. Amyloidogenic processing of beta-amyloid precursor protein in intracellular compartments. Neurology. 2006;66:569-73.

19. Zhang H, Ma Q, Zhang YW, Xu H. Proteolytic processing of Alzheimer's beta-amyloid precursor protein. J Neurochem. 2012;120 Suppl 1:9-21.

20. Zhang YW, Thompson $\mathrm{R}$, Zhang $\mathrm{H}, \mathrm{Xu} \mathrm{H}$. APP processing in Alzheimer's disease. Mol Brain. 2011;4:3-6606-4-3.

21. Hu X, Li X, Zhao M, Gottesdiener A, Luo W, Paul S. Tau pathogenesis is promoted by Abeta1-42 but not Abeta1-40. Mol Neurodegener. 2014;9:52.

22. Kuperstein I, Broersen K, Benilova I, Rozenski J, Jonckheere W, Debulpaep M, et al. Neurotoxicity of Alzheimer's disease Abeta peptides is induced by small changes in the Abeta42 to Abeta40 ratio. EMBO J. 2010;29:3408-20.

23. De Felice FG, Velasco PT, Lambert MP, Viola K, Fernandez SJ, Ferreira ST, et al. Abeta oligomers induce neuronal oxidative stress through an $\mathrm{N}$ methyl-D-aspartate receptor-dependent mechanism that is blocked by the Alzheimer drug memantine. J Biol Chem. 2007;282:11590-601.

24. Coleman PD, Yao PJ. Synaptic slaughter in Alzheimer's disease. Neurobio Aging. 2003;24:1023-7.

25. Jonsson T, Atwal JK, Steinberg S, Snaedal J, Jonsson PV, Bjornsson S, et al. A mutation in APP protects against Alzheimer's disease and age-related cognitive decline. Nature. 2012;488:96-9.

26. Hashimoto Y, Matsuoka M. A mutation protective against Alzheimer's disease renders amyloid beta precursor protein incapable of mediating neurotoxicity. J Neurochem. 2014;130:291-300.

27. Karran E, Mercken M, De Strooper B. The amyloid cascade hypothesis for Alzheimer's disease: an appraisal for the development of therapeutics. Nat Rev Drug Discov. 2011;10:698-712.

28. Kopeikina KJ, Hyman BT, Spires-Jones TL. Soluble forms of tau are toxic in Alzheimer's disease. Transl Neurosci. 2012;3:223-33.

29. Walsh DM, Klyubin I, Fadeeva JV, Cullen WK, Anwyl R, Wolfe MS, et al, Naturally secreted oligomers of amyloid beta protein potently inhibit hippocampal long-term potentiation in vivo. Nature. 2002;416:535-9.

30. Selkoe DJ. Soluble oligomers of the amyloid beta-protein impair synaptic plasticity and behavior. Behav Brain Res. 2008;192:106-13.

31. Frandemiche ML, De Seranno S, Rush T, Borel E, Elie A, Arnal I, et al. Activity-dependent tau protein translocation to excitatory synapse is disrupted by exposure to amyloid-beta oligomers. J Neurosci. 2014;34:6084-97.

32. Ittner LM, Ke YD, Delerue F, Bi M, Gladbach A, van Eersel J, et al. Dendritic function of tau mediates amyloid-beta toxicity in Alzheimer's disease mouse models. Cell. 2010;142:387-97.

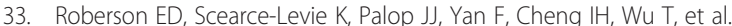
Reducing endogenous tau ameliorates amyloid beta-induced deficits in an Alzheimer's disease mouse model. Science. 2007:316:750-4.

34. Wildsmith KR, Holley M, Savage JC, Skerrett R, Landreth GE. Evidence for impaired amyloid beta clearance in Alzheimer's disease. Alzheimers Res Ther. 2013;5:33.

35. Chen X, Lin R, Chang L, Xu S, Wei X, Zhang J, et al. Enhancement of long-term depression by soluble amyloid beta protein in rat hippocampus is mediated by metabotropic glutamate receptor and involves activation of p38MAPK, STEP and caspase-3. Neuroscience. 2013;253:435-43.
36. Jo J, Whitcomb DJ, Olsen KM, Kerrigan TL, Lo SC, Bru-Mercier G, et al. Abeta(1-42) inhibition of LTP is mediated by a signaling pathway involving caspase-3, Akt1 and GSK-3beta. Nat Neurosci. 2011;14:545-7.

37. Liu CC, Tsai CW, Deak F, Rogers J, Penuliar M, Sung YM, et al. Deficiency in LRP6-mediated Wnt signaling contributes to synaptic abnormalities and amyloid pathology in Alzheimer's disease. Neuron. 2014;84:63-77.

38. Peineau S, Taghibiglou C, Bradley C, Wong TP, Liu L, Lu J, et al. LTP inhibits LTD in the hippocampus via regulation of GSK3beta. Neuron. 2007;53:703-17.

39. de la Monte SM. Brain insulin resistance and deficiency as therapeutic targets in Alzheimer's disease. Curr Alzheimer Res. 2012;9:35-66.

40. Han X, Ma Y, Liu X, Wang L, Qi S, Zhang Q, et al. Changes in insulin-signaling transduction pathway underlie learning/memory deficits in an Alzheimer's disease rat model. J Neural Transm. 2012;119:1407-16.

41. Zhao WQ, Chen H, Quon MJ, Alkon DL. Insulin and the insulin receptor in experimental models of learning and memory. Eur J Pharmacol. 2004:490:71-81.

42. Cerpa W, Godoy JA, Alfaro I, Farias GG, Metcalfe MJ, Fuentealba R, et al. Wnt-7a modulates the synaptic vesicle cycle and synaptic transmission in hippocampal neurons. J Biol Chem. 2008;283:5918-27.

43. Cerpa W, Gambrill A, Inestrosa NC, Barria A. Regulation of NMDA-receptor synaptic transmission by Wht signaling. J Neurosci. 2011;31:9466-71.

44. Jacob CP, Koutsilieri E, Bartl J, Neuen-Jacob E, Arzberger T, Zander N, et al. Alterations in expression of glutamatergic transporters and receptors in sporadic Alzheimer's disease. J Alzheimers Dis. 2007:11:97-116.

45. Wang Y, Briz V, Chishti A, Bi X, Baudry M. Distinct roles for mu-calpain and $\mathrm{m}$-calpain in synaptic NMDAR-mediated neuroprotection and extrasynaptic NMDAR-mediated neurodegeneration. J Neurosci. 2013:33:18880-92.

46. Dominguez E, Chin TY, Chen CP, Wu TY. Management of moderate to severe Alzheimer's disease: focus on memantine. Taiwan J Obstet Gynecol. 2011;50:415-23.

47. Tucci P, Mhillaj E, Morgese MG, Colaianna M, Zotti M, Schiavone S, et al. Memantine prevents memory consolidation failure induced by soluble beta amyloid in rats. Front Behav Neurosci. 2014;8:332.

48. Xia P, Chen HS, Zhang D, Lipton SA. Memantine preferentially blocks extrasynaptic over synaptic NMDA receptor currents in hippocampal autapses. J Neurosci. 2010;30:11246-50.

49. Sinforiani E, Pasotti C, Chiapella L, Malinverni P, Zucchella C. Memantine in Alzheimer's disease: experience in an Alzheimer's disease assessment unit. Aging Clin Exp Res. 2012;24:193-6.

50. Emre M, Tsolaki M, Bonuccelli U, Destee A, Tolosa E, Kutzelnigg A, et al. Memantine for patients with Parkinson's disease dementia or dementia with Lewy bodies: a randomised, double-blind, placebo-controlled trial. Lancet Neurol. 2010;9:969-77.

51. Wesnes KA, Aarsland D, Ballard C, Londos E. Memantine improves attention and episodic memory in Parkinson's disease dementia and dementia with Lewy bodies. Int J Geriatr Psychiatry. 2014;30:46-54.

52. Ballatore C, Lee VM, Trojanowski JQ. Tau-mediated neurodegeneration in Alzheimer's disease and related disorders. Nat Rev Neurosci. 2007;8:663-72.

53. Li S, Jin M, Koeglsperger T, Shepardson NE, Shankar GM, Selkoe DJ. Soluble Abeta oligomers inhibit long-term potentiation through a mechanism involving excessive activation of extrasynaptic NR2B-containing NMDA receptors. J Neurosci. 2011;31:6627-38.

54. Hoover BR, Reed MN, Su J, Penrod RD, Kotilinek LA, Grant MK, et al. Tau mislocalization to dendritic spines mediates synaptic dysfunction independently of neurodegeneration. Neuron. 2010;68:1067-81.

55. Nakazawa T, Komai S, Tezuka T, Hisatsune C, Umemori H, Semba K, et al. Characterization of Fyn-mediated tyrosine phosphorylation sites on GluR epsilon 2 (NR2B) subunit of the N-methyl-D-aspartate receptor. J Biol Chem. 2001;276:693-9.

56. Rong Y, Lu X, Bernard A, Khrestchatisky M, Baudry M. Tyrosine phosphorylation of ionotropic glutamate receptors by Fyn or Src differentially modulates their susceptibility to calpain and enhances their binding to spectrin and PSD-95. J Neurochem. 2001;79:382-90.

57. Salter MW, Kalia LV. Src kinases: a hub for NMDA receptor regulation. Nat Rev Neurosci. 2004;5:317-28.

58. Graff J, Rei D, Guan JS, Wang WY, Seo J, Hennig KM, et al. An epigenetic blockade of cognitive functions in the neurodegenerating brain. Nature. 2012;483:222-6. 
59. Bie B, Wu J, Yang H, Xu JJ, Brown DL, Naguib M. Epigenetic suppression of neuroligin 1 underlies amyloid-induced memory deficiency. Nat Neurosci. 2014;17:223-31.

60. Luo P, Li X, Fei Z, Poon W. Scaffold protein Homer 1: implications for neurological diseases. Neurochem Int. 2012;61:731-8.

61. Mishiba T, Tanaka M, Mita N, He X, Sasamoto K, Itohara S, et al. Cdk5/p35 functions as a crucial regulator of spatial learning and memory. Mol Brain. 2014;7:82.

62. Sun S, Zhang H, Liu J, Popugaeva E, Xu NJ, Feske S, et al. Reduced synaptic STIM2 expression and impaired store-operated calcium entry cause destabilization of mature spines in mutant presenilin mice. Neuron. 2014;82:79-93.

63. Liu J, Chang L, Roselli F, Almeida OF, Gao X, Wang X, et al. Amyloid-beta induces caspase-dependent loss of PSD-95 and synaptophysin through NMDA receptors. J Alzheimers Dis. 2010;22:541-56.

64. Ni R, Marutle A, Nordberg A. Modulation of alpha7 nicotinic acetylcholine receptor and fibrillar amyloid-beta interactions in Alzheimer's disease brain. J Alzheimers Dis. 2013;33:841-51.

65. Rushworth JV, Griffiths HH, Watt NT, Hooper NM. Prion protein-mediated toxicity of amyloid-beta oligomers requires lipid rafts and the transmembrane LRP1. J Biol Chem. 2013;288:8935-51.

66. Calabresi P, Maj R, Pisani A, Mercuri NB, Bernardi G. Long-term synaptic depression in the striatum: physiological and pharmacological characterization. J Neurosci. 1992;12:4224-33.

67. Ferrer I. Neurons and their dendrites in frontotemporal dementia. Dement Geriatr Cogn Disord. 1999;10 Suppl 1:55-60.

68. Picconi B, Centonze D, Hakansson K, Bernardi G, Greengard P, Fisone G, et al. Loss of bidirectional striatal synaptic plasticity in L-DOPA-induced dyskinesia. Nat Neurosci. 2003;6:501-6.

69. Raymond LA, Andre VM, Cepeda C, Gladding CM, Milnerwood AJ, Levine MS. Pathophysiology of Huntington's disease: time-dependent alterations in synaptic and receptor function. Neuroscience. 2011;198:252-73.

70. Lesage S, Brice A. Parkinson's disease: from monogenic forms to genetic susceptibility factors. Hum Mol Genet. 2009;18:R48-59.

71. Kitada T, Asakawa S, Hattori N, Matsumine H, Yamamura Y, Minoshima S, et al. Mutations in the parkin gene cause autosomal recessive juvenile parkinsonism. Nature. 1998;392:605-8.

72. Zarranz JJ, Alegre J, Gomez-Esteban JC, Lezcano E, Ros R, Ampuero I, et al. The new mutation, E46K, of alpha-synuclein causes Parkinson and Lewy body dementia. Ann Neurol. 2004;55:164-73.

73. Zimprich A, Biskup S, Leitner $P$, Lichtner $P$, Farrer M, Lincoln S, et al. Mutations in LRRK2 cause autosomal-dominant parkinsonism with pleomorphic pathology. Neuron. 2004;44:601-7.

74. Burre J, Sharma M, Tsetsenis T, Buchman V, Etherton MR, Sudhof TC. Alpha-synuclein promotes SNARE-complex assembly in vivo and in vitro. Science. 2010;329:1663-7

75. Spillantini MG, Schmidt ML, Lee VM, Trojanowski JQ, Jakes R, Goedert M. Alpha-synuclein in Lewy bodies. Nature. 1997;388:839-40.

76. Dalfo E, Gomez-Isla T, Rosa JL, Nieto Bodelon M, Cuadrado Tejedor M, Barrachina $M$, et al. Abnormal alpha-synuclein interactions with Rab proteins in alpha-synuclein A30P transgenic mice. J Neuropathol Exp Neurol. 2004;63:302-13.

77. Dalfo E, Barrachina M, Rosa JL, Ambrosio S, Ferrer I. Abnormal alpha-synuclein interactions with rab3a and rabphilin in diffuse Lewy body disease. Neurobiol Dis. 2004;16:92-7.

78. Piccoli G, Condliffe SB, Bauer M, Giesert F, Boldt K, De Astis S, et al. LRRK2 controls synaptic vesicle storage and mobilization within the recycling pool. J Neurosci. 2011;31:2225-37.

79. Shin N, Jeong H, Kwon J, Heo HY, Kwon JJ, Yun HJ, et al. LRRK2 regulates synaptic vesicle endocytosis. Exp Cell Res. 2008;314:2055-65

80. Xiong Y, Coombes CE, Kilaru A, Li X, Gitler AD, Bowers WJ, et al. GTPase activity plays a key role in the pathobiology of LRRK2. PLOS Genet. 2010;6:e1000902.

81. Anonymous. A novel gene containing a trinucleotide repeat that is expanded and unstable on Huntington's disease chromosomes. The Huntington's Disease Collaborative Research Group. Cell. 1993;72:971-83.

82. Ross CA, Tabrizi SJ. Huntington's disease: from molecular pathogenesis to clinical treatment. Lancet Neurol. 2011;10:83-98.

83. Faideau M, Kim J, Cormier K, Gilmore R, Welch M, Auregan G, et al. In vivo expression of polyglutamine-expanded huntingtin by mouse striatal astrocytes impairs glutamate transport: a correlation with Huntington's disease subjects. Hum Mol Genet. 2010;19:3053-67.

84. Estrada-Sanchez AM, Rebec GV. Corticostriatal dysfunction and glutamate transporter 1 (GLT1) in Huntington's disease: interactions between neurons and astrocytes. Basal Ganglia. 2012;2:57-66.

85. Miller BR, Dorner JL, Bunner KD, Gaither TW, Klein EL, Barton SJ, et al. Up-regulation of GLT1 reverses the deficit in cortically evoked striatal ascorbate efflux in the R6/2 mouse model of Huntington's disease. J Neurochem. 2012;121:629-38.

86. Corti C, Battaglia G, Molinaro G, Riozzi B, Pittaluga A, Corsi M, et al. The use of knock-out mice unravels distinct roles for mGlu2 and mGlu3 metabotropic glutamate receptors in mechanisms of neurodegeneration/ neuroprotection. J Neurosci. 2007;27:8297-308.

87. Ondo WG, Mejia NI, Hunter CB. A pilot study of the clinical efficacy and safety of memantine for Huntington's disease. Parkinsonism Relat Disord. 2007;13:453-4.

88. Brun A, Liu X, Erikson C. Synapse loss and gliosis in the molecular layer of the cerebral cortex in Alzheimer's disease and in frontal lobe degeneration. Neurodegeneration. 1995;4:171-7.

89. Liu X, Erikson C, Brun A. Cortical synaptic changes and gliosis in normal aging, Alzheimer's disease and frontal lobe degeneration. Dementia. 1996;7:128-34

90. Mackenzie IR, Neumann M, Bigio EH, Cairns NJ, Alafuzoff I, Kril J, et al. Nomenclature for neuropathologic subtypes of frontotemporal lobar degeneration: consensus recommendations. Acta Neuropathol. 2009;117:15-8

91. DeMay BS, Bai X, Howard L, Occhipinti P, Meseroll RA, Spiliotis ET, et al. Septin filaments exhibit a dynamic, paired organization that is conserved from yeast to mammals. J Cell Biol. 2011;193:1065-81.

92. Yang YM, Fedchyshyn MJ, Grande G, Aitoubah J, Tsang CW, Xie H, et al. Septins regulate developmental switching from microdomain to nanodomain coupling of $\mathrm{Ca}(2+)$ influx to neurotransmitter release at a central synapse. Neuron. 2010;67:100-15.

93. Amin ND, Zheng YL, Kesavapany S, Kanungo J, Guszczynski T, Sihag RK, et al. Cyclin-dependent kinase 5 phosphorylation of human septin SEPT5 (hCDCrel-1) modulates exocytosis. J Neurosci. 2008;28:3631-43.

94. Ito H, Atsuzawa K, Morishita R, Usuda N, Sudo K, Iwamoto I, et al. Sept8 controls the binding of vesicle-associated membrane protein 2 to synaptophysin. J Neurochem. 2009;108:867-80.

95. Hall PA, Russell SE. Mammalian septins: dynamic heteromers with roles in cellular morphogenesis and compartmentalization. J Pathol. 2012;226:287-99.

96. Mavrakis M, Azou-Gros Y, Tsai FC, Alvarado J, Bertin A, Iv F, et al. Septins promote $\mathrm{F}$-actin ring formation by crosslinking actin filaments into curved bundles. Nat Cell Biol. 2014;16:322-34.

97. Munoz-Soriano V, Paricio N. Overexpression of Septin 4, the Drosophila homologue of human CDCrel-1, is toxic for dopaminergic neurons. Eur J Neurosci. 2007;26:3150-8.

98. Kinoshita A, Kinoshita M, Akiyama H, Tomimoto H, Akiguchi I, Kumar S, et al. Identification of septins in neurofibrillary tangles in Alzheimer's disease. Am J Pathol. 1998;153:1551-60.

99. Barr AM, Young CE, Sawada K, Trimble WS, Phillips AG, Honer WG. Abnormalities of presynaptic protein CDCrel-1 in striatum of rats reared in social isolation: relevance to neural connectivity in schizophrenia. Eur J Neurosci. 2004:20:303-7.

100. Mostowy S, Cossart P. Septins: the fourth component of the cytoskeleton. Nat Rev Mol Cell Biol. 2012;13:183-94.

101. Beise N, Trimble W. Septins at a glance. J Cell Sci. 2011;124:4141-6.

102. Peterson EA, Petty EM. Conquering the complex world of human septins: implications for health and disease. Clin Genet. 2010;77:511-24.

103. Oh Y, Bi E. Septin structure and function in yeast and beyond. Trends Cell Biol. 2011;21:141-8.

104. Weirich CS, Erzberger JP, Barral Y. The septin family of GTPases: architecture and dynamics. Nat Rev Mol Cell Biol. 2008;9:478-89.

105. Sirajuddin M, Farkasovsky M, Zent E, Wittinghofer A. GTP-induced conformational changes in septins and implications for function. Proc Natl Acad Sci U S A. 2009;106:16592-7.

106. Ageta-Ishihara N, Yamakado H, Morita T, Hattori S, Takao K, Miyakawa T, Takahashi R, Kinoshita M. Chronic overload of SEPT4, a parkin substrate that aggregates in Parkinson's disease, causes behavioral alterations but not neurodegeneration in mice. Mol Brain. 2013;6:35-6606-6-35. 
107. Dong Z, Ferger B, Paterna JC, Vogel D, Furler S, Osinde M, et al. Dopamine-dependent neurodegeneration in rats induced by viral vector-mediated overexpression of the parkin target protein, CDCrel-1. Proc Natl Acad Sci U S A. 2003;100:12438-43.

108. Gozal YM, Seyfried NT, Gearing M, Glass JD, Heilman CJ, Wuu J, et al Aberrant septin 11 is associated with sporadic frontotemporal lobar degeneration. Mol Neurodegener. 2011;6:82-1326-6-82.

109. Ihara M, Yamasaki N, Hagiwara A, Tanigaki A, Kitano A, Hikawa R, et al. Sept4, a component of presynaptic scaffold and Lewy bodies, is required for the suppression of alpha-synuclein neurotoxicity. Neuron. 2007:53:519-33.

110. Pissuti Damalio JC, Garcia W, Alves Macedo JN, de Almeida Marques I, Andreu JM, Giraldo R, et al. Self assembly of human septin 2 into amyloid filaments. Biochimie. 2012;94:628-36.

111. Zhang Y, Gao J, Chung KK, Huang H, Dawson VL, Dawson TM. Parkin functions as an E2-dependent ubiquitin- protein ligase and promotes the degradation of the synaptic vesicle-associated protein, CDCrel-1. Proc Natl Acad Sci U S A. 2000;97:13354-9.

112. Musunuri S, Wetterhall M, Ingelsson M, Lannfelt L, Artemenko K, Bergquist J, et al. Quantification of the Brain Proteome in Alzheimer's Disease Using Multiplexed Mass Spectrometry. J Proteome Res. 2014;13:2056-68.

113. Takehashi M, Alioto T, Stedeford T, Persad A, Banasik M, Masliah E, et al. Septin 3 gene polymorphism in Alzheimer's disease. 2004;11:263-70.

114. Hanai N, Nagata K, Kawajiri A, Shiromizu T, Saitoh N, Hasegawa Y, et al. Biochemical and cell biological characterization of a mammalian septin, Sept11. FEBS Lett. 2004;568:83-8.

115. Cairns NJ, Lee VM, Trojanowski JQ. The cytoskeleton in neurodegenerative diseases. J Pathol. 2004;204:438-49.

116. Czeredys M, Gruszczynska-Biegala J, Schacht T, Methner A, Kuznicki J. Expression of genes encoding the calcium signalosome in cellular and transgenic models of Huntington's disease. Front Mol Neurosci. 2013;6:42.

117. Taniguchi M, Taoka M, Itakura M, Asada A, Saito T, Kinoshita M, et al. Phosphorylation of adult type Sept5 (CDCrel-1) by cyclin-dependent kinase 5 inhibits interaction with syntaxin-1. J Biol Chem. 2007:282:7869-76.

118. Beites $C L$, Xie H, Bowser R, Trimble WS. The septin CDCrel-1 binds syntaxin and inhibits exocytosis. Nat Neurosci. 1999;2:434-9.

119. Shukla V, Skuntz S, Pant HC. Deregulated Cdk5 activity is involved in inducing Alzheimer's disease. Arch Med Res. 2012:43:655-62.

120. Son JH, Kawamata H, Yoo MS, Kim DJ, Lee YK, Kim S, et al. Neurotoxicity and behavioral deficits associated with Septin 5 accumulation in dopaminergic neurons. J Neurochem. 2005;94:1040-53.

121. Kinoshita N, Kimura K, Matsumoto N, Watanabe M, Fukaya M, Ide C. Mammalian septin Sept2 modulates the activity of GLAST, a glutamate transporter in astrocytes. Genes Cells. 2004;9:1-14.

122. Sitz JH, Baumgartel K, Hammerle B, Papadopoulos C, Hekerman P, Tejedor FJ, et al. The Down syndrome candidate dual-specificity tyrosine phosphorylation-regulated kinase 1A phosphorylates the neurodegeneration-related septin 4. Neuroscience. 2008;157:596-605.

123. Ihara $\mathrm{M}$, Tomimoto $\mathrm{H}$, Kitayama $\mathrm{H}$, Morioka $\mathrm{Y}$, Akiguchi I, Shibasaki $\mathrm{H}$, et al. Association of the cytoskeletal GTP-binding protein Sept4/H5 with cytoplasmic inclusions found in Parkinson's disease and other synucleinopathies. J Biol Chem. 2003;278:24095-102.

124. Kissel H, Georgescu MM, Larisch S, Manova K, Hunnicutt GR, Steller H. The Sept4 septin locus is required for sperm terminal differentiation in mice. Dev Cell. 2005;8:353-64.

125. Garcia-Fernandez M, Kissel H, Brown S, Gorenc T, Schile AJ, Rafii S, et al. Sept4/ARTS is required for stem cell apoptosis and tumor suppression. Genes Dev. 2010;24:2282-93.

126. Tokhtaeva E, Capri J, Marcus EA, Whitelegge JP, Khuzakhmetova V,

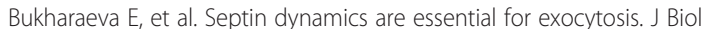
Chem. 2015;290:5280-97.

127. Kvartsberg H, Duits FH, Ingelsson M, Andreasen N, Ohrfelt A, Andersson K et al. Cerebrospinal fluid levels of the synaptic protein neurogranin correlates with cognitive decline in prodromal Alzheimer's disease. Alzheimers Dement 2014, doi:10.1016/j.jalz.2014.10.009.

128. Brinkmalm A, Brinkmalm G, Honer WG, Frolich L, Hausner L, Minthon L, et al. SNAP-25 is a promising novel cerebrospinal fluid biomarker for synapse degeneration in Alzheimer's disease. Mol Neurodegener. 2014;9:53-1326. 9-53.

129. Katsuno M, Tanaka F, Sobue G. Perspectives on molecular targeted therapies and clinical trials for neurodegenerative diseases. J Neuro Neurosurg Psychiatry. 2012;83:329-35.

\section{Submit your next manuscript to BioMed Central and take full advantage of:}

- Convenient online submission

- Thorough peer review

- No space constraints or color figure charges

- Immediate publication on acceptance

- Inclusion in PubMed, CAS, Scopus and Google Scholar

- Research which is freely available for redistribution

Submit your manuscript at www.biomedcentral.com/submit 